\title{
Legislative Efforts to Reduce Concussions in Youth Sports: An Analysis of State Concussion Statutes
}

\author{
Sungwon Kim and Daniel P. Connaughton \\ University of Florida
}

\author{
John Spengler \\ Texas A\&M University
}

\author{
Jong Hoon Lee \\ University of New Mexico
}

\begin{abstract}
Sport-related concussions are a serious public health issue. While concussions are prevalent among all age groups, youth sport participants are at a greater risk of sustaining such injury due to their immature brain structure and the lack of concussion management policies at the organizational level compared with those found in intercollegiate and professional sports (Kim, Spengler, \& Connaughton, 2016). To address this problem, legislation has been adopted in all 50 states and the District of Columbia to mandate some of the standardized measures of concussion management. The purpose of this study was to review the existing state concussion statutes. The statutes were obtained via the LEXIS/NEXIS and West Law databases. Key categories were selected by the researchers and language was compared among statutes. Although the vast majority of concussion statutes shared some similarities, a comprehensive review revealed wide inconsistencies in language. Suggestions that promote more consistency among statutes on language that is beneficial to the safety of youth, as well as recommendations for possible amendments, are provided in the discussion.
\end{abstract}

Keywords: head injury, TBI, legislation, athletics

Traumatic brain injuries (TBI), commonly known as concussions, have recently been gaining public attention worldwide. A concussion is a brain injury with a traumatically induced transient disturbance of brain function (Harmon et al., 2013). Most concussions are typically caused by a blow to the head, resulting

\footnotetext{
Kim is with the Dept. of Tourism, Recreation and Sport Management, University of Florida, Gainesville, FL. Connaughton is with the Dept. of Tourism, Recreation and Sport Management, University of Florida, Gainesville, FL. Spengler is with the Dept. of Health Promotion and Community Health Sciences, Texas A\&M University, College Station, TX. Lee is with the Dept. of Health, Exercise and Sport Sciences, University of New Mexico, Albuquerque, NM. Please address author correspondence to Daniel Connaughton at danc@hhp.ufl.edu
} 
in temporary impairment of neurological functions. Other clinical symptoms may include headaches, dizziness, difficulty in concentration, confusion, nausea, and sensitivity to light (Castile, Collins, McIlvain, \& Comstock, 2012; Marar, McIlvain, Fields, \& Comstock, 2012). The most recent data from the Centers for Disease Control and Prevention (CDC) estimated that between 1.6 and 3.8 million individuals suffer sport-related concussions in the United States annually (Langlois, Rutland-Brown, \& Wald, 2006).

Children and adolescents are especially vulnerable to TBI and may experience a longer recovery period than adults because of premature brain structures (Karlin, 2011). Children between the ages of 8 and 13, and adolescents between the ages of 14 and 19 accounted for approximately $58 \%$ and $46 \%$, respectively, of all emergency department visits due to concussive injuries (Bakhos, Lockhart, Myers, \& Linakis, 2010). In addition, 30\% of the concussions sustained by young people between the ages of 5 and 19 can be attributed to sport-related activities (Bakhos et al., 2010; Meehan, d'Hemecourt, \& Comstock, 2010). Macpherson, Fridman, Scolnik, Corallo, \& Guttmann (2014) found that between 2003 and 2010 the rate of concussions (per 100,000 pediatric department and office visits) has increased from 466.7 to 754.3 for youth males, and from 208.6 to 440.7 for youth females. Similarly, in high school sports, the rate of concussions increased from 0.23 to 0.51 (per 1,000 athlete exposures) between the 2005-2006 and 2011-2012 academic years, respectively (Rosenthal, Foraker, Collins, \& Comstock, 2014).

In addition to young athletes being more prone to concussions, a lack of youth sport stakeholders' (i.e., athletes' and parents') knowledge in recognizing the signs and symptoms of concussions increases the risk factors associated with such injuries (Gourley, Valovich McLeod, \& Bay, 2010). For example, Rivara et al. (2014) reported that $69 \%$ of high school football and girls' soccer athletes who had experienced a concussion played with symptoms, and many of them did not report such symptoms to their coach. The higher risk of concussions among young athletes is further exacerbated by the lack of risk management measures typically employed at the youth sport level. For instance, while baseline cognitive testing is an effective method for evaluating a head injury by comparing an athlete's pre- and postconcussion scores, most competitive youth sport organizations are medically and financially unable to implement such procedures. A team doctor and/or athletic trainer is not typically present at most youth sport events, which creates further challenges in managing and evaluating concussions despite the fact that appropriate sideline management can improve outcomes and decrease medical costs associated with sport-related concussions (Gianotti \& Hume, 2007). The lack of organizational policies and/or procedures in detecting a concussion may contribute to a young athlete returning to sports prematurely. In fact, athletes who return prematurely from a concussion, are three to six times more likely to incur "second-impact syndrome" (Bey \& Ostick, 2009; Cantu \& Register-Mihalik, 2011), which can lead to severe brain damage (Thomas et al., 2011).

In response to the severity and increasing rate of youth sport concussions, many risk management strategies have been implemented at various organizational levels. Some of these strategies have included rule changes, equipment/facility upgrades, and educational initiatives (Benson et al., 2013). In addition to these strategies, legislative efforts have also been implemented. The first concussion statute, known as the Lystedt Law, was enacted in 2009 by the state of Washington. It was named 
after Zachary Lystedt, a middle school football player, who suffered a catastrophic brain injury when he was allowed to return to play after sustaining a concussion earlier in a game. With the Lystedt Law receiving widespread public attention, all other states and the District of Columbia had implemented similar laws by April 2014 (Lowrey, 2014). The establishment of state concussion laws occurred in a relatively short time period, due, in part, to support from various sport governing bodies and organizations such as the National Football League (NFL), National Collegiate Athletics Association (NCAA), American College of Sports Medicine (ACSM), and CDC. Although variations exist among state statutes, the vast majority of concussion laws are based on three common provisions: (1) concussion education to relevant stakeholders, (2) mandatory removal of athletes who exhibit signs and symptoms of concussion, and (3) requiring clearance by health care providers to return to play (RTP). The primary intent of these laws is to increase awareness, diagnosis, and management of concussions among various stakeholders involved in youth sports, including, but not limited to, coaches, parents/guardians, athletic trainers, and referees/officials.

Although it may be premature to evaluate the effectiveness of state concussion laws, studies have suggested positive outcomes. Since the enactment of the Lystedt Law in the state of Washington, educational materials were more regularly disseminated to high school football and soccer coaches and have improved their overall concussion knowledge (Chrisman, Schiff, Chung, Herring, \& Rivara, 2014). Concussion laws have also played an important role in the reporting of concussions and the utilization of related health care services. The number of reported concussions increased significantly for the first and second years following the enactment of the Lystedt Law, presumably due to a higher incidence of reporting. In addition, an athlete's RTP period was lengthened by 6.9 days compared with the RTP period before the Lystedt Law was passed (Bompadre et al., 2014). Similarly, Mackenzie et al. (2015) investigated emergency department visits of pediatric populations in Rhode Island and found that the overall rate of concussion reporting doubled since the implementation of Rhode Island's concussion legislation. In addition, another study found that states with concussion legislation saw an increase in the number of people seeking health care services due to concussive injuries by $92 \%$, whereas states without concussion laws (during the time of review) had observed only a $75 \%$ increase in such pursuits (Gibson, Herring, Kutcher, \& Broglio, 2015).

Although the vast majority of state concussion statutes center on the three themes found in Washington's Lystedt Law, not all states follow such model. Analysis of the concussion statutes in several previous studies identified considerable variations between states (Harvey, 2013; Lowrey, 2014; Tomei, Doe, Prestigiacomo, \& Gandhi, 2012). In addition, adhering to state concussion statutes can often be challenging due to its ambiguous language. For instance, although nearly all states mandate removing an athlete suspected of having a concussion from a game or practice, there are huge discrepancies in the statutes as to who has the authority to make such decisions. While some statutes specifically authorize a licensed physician, licensed neuropsychologist, or certified athletic trainer to remove athletes displaying signs and/or symptoms of a concussion, there are statutes that merely state "an appropriate health professional" as being eligible for determining player removal. Youth sport stakeholders, therefore, have the burden of interpreting who qualifies as "an appropriate health professional." Additionally, methods of providing 
appropriate concussion education are not specified in most statutes, although some statutes specify the provision of informational sheets for education. Indeed, what constitutes sufficient education remains controversial, as previous research has suggested that passive forms of education (e.g., poster, information card, webpage, etc.) are not efficacious ways to lead to behavioral changes (Giguere et al., 2012).

Before all states passed concussion laws, research examining such statutes had been conducted. Tomei et al. (2012) reviewed and compared concussion statutes in 43 states and the District of Columbia (7 states had pending legislation at the time the review was conducted). The selected categories of legislative components in that review included the legislation's targeted population, education requirement, removal-from-play criteria, clearance for RTP stipulation, and noncompliance procedures. The key findings indicated that, although concussion education is the primary legislative intent, only $48 \%$ of the states required that coaches receive formal training. Moreover, 32\% of the states with concussion laws mandated concussion education by disseminating an information sheet or other unspecified methods, while concussion education was optional in $20 \%$ of the states. Many statutes also stressed the importance of concussion education for athletes and parents; $88.7 \%$ of the states required parental education and $86 \%$ of states required athlete education. Seventy-five percent of the states required removing athletes with concussion-suspected symptoms. Individuals with an authority to evaluate, treat, and clear a concussion-sustained athlete for RTP varied greatly among states (Tomei et al., 2012).

Similarly, Harvey (2013) conducted a comprehensive review of concussion statutes in 45 states (including District of Columbia) to investigate the relationship between the content of legislation and prevailing scientific knowledge. The analysis focused on categories such as removal from play, evaluation and clearance to play, information distribution, coach's training, and liability waivers. Forty states had a removal-from-play mandate that specifically required the removal of an athlete for a minimum of $24 \mathrm{hr}$ after a suspected concussion. Another category, "evaluation and clearance to play," was analyzed in terms of who was authorized to remove and clear a concussed athlete or one with a suspected concussion. Designated individuals for removing athletes varied greatly among states. The study also found that only 26 out of the 45 states explicitly required a health care professional to receive training in the management and identification of TBI. Concussion education was a prominent component of legislation, illustrated by 34 states having such a requirement. The legislation would typically require the distribution of an information sheet to parents/guardians and athletes, with some states requiring signatures from these parties to ensure that the dissemination of such information has occurred. Despite the presence of such language in the majority of statutes, the language and substance of the educational requirements lacked sufficient details, which creates challenges to implementation. Of the 45 states with concussion statutes, 25 had concussion-training requirements for coaches. However, specific training methods or programs had not been clearly identified by the majority of states. Finally, 16 out of the 45 statutes explicitly addressed liability limitation or protection for youth sport stakeholders (e.g., coaches, health care providers, governing bodies, etc.) for civil litigation brought by parents of a concussed athlete. The general premise of this component is to provide legal protection to those who comply with state concussion laws in good faith should athletes sustain injury or death (Harvey, 2013). 
Finally, a more recent study conducted by Lowrey (2014) examined 22 concussion statutes that had been substantially modified since their original passage. For instance, seven states expanded their laws to cover recreational youth sports, charter/ private schools, and sport organizations utilizing school property. In addition, 19 states revised original language to tighten and clarify the law's intent. Some of these amendments included adding athletic trainers to the eligible personnel who can make RTP decisions, strengthening education and informed consent requirements for parents, training requirements for coaches and officials, and requiring the establishment of concussion protocol for concussion-suspected athletes (including academic adjustments). Moreover, three states added language that required that coaches be educated about the appropriate number of games and duration of full-contact practices and scrimmages to limit potentially dangerous contact. For example, in 2014, California revised its statutes to limit full-contact practices to 90 min per day and twice per week (Cal. Educ. Code, 2014b). Another revision involved the regulation of sports equipment. Concussion laws in California and Texas established high school football helmet standards that incorporated age and helmet reconditioning standards (Cal. Educ. Code, 2014a; Tex. Educ. Code, 2011).

To our knowledge, no studies have comprehensively reviewed the major components of concussion statutes after legislation was enacted in all states and the District of Columbia (hereafter 51 states). Given the variation among the state concussion legislation, the purpose of this study was to conduct a comprehensive analysis of concussion statutes in 51 states. In addition to the language that was analyzed by previous researchers (Harvey, 2013; Lowrey, 2014; Tomei et al., 2012), the current study expanded and added new categories for analysis. Understanding the components of these laws is an important step in assisting law and policy makers to further improve the content and implementation of such legislation.

\section{Method}

Concussion statutes from 51 states were reviewed. All of the statutes were enacted and/or amended between 2009 and 2015. The primary search for the statutes was accomplished by utilizing both LEXIS/NEXIS and WESTLAW. After an initial search of sport concussion legislation via LEXIS/NEXIS, a WESTLAW search was conducted. The keywords used in the search included youth sport concussion, concussion state laws, traumatic brain injury and sport, concussion protocols and guidelines, concussion and school sports, and concussion and student athletes. To cross-reference the search results, published studies (Harvey, 2013; Lowrey, 2014; Tomei et al., 2012) and publicly available information on youth sport concussion laws (Public Health Law Research, 2015) were reviewed. Once the identified statutes were cross-referenced and reviewed, the researchers identified the most relevant contents of legislation with possible ambiguities in language and jurisdictional inconsistencies between the statutes. The selected content was read, analyzed, and placed into a descriptive table by categories. The categories included participant's age, law applicability setting, youth sport definition, covered and excluded activities, youth sport program applicability (i.e., interscholastic versus private/recreational sports), fee required to trigger concussion safety mandate for nonschool sports, concussion education requirement, mandatory concussion 
training/course requirement, removal of athlete requirement, designated party for removal of athletes, medical clearance for return-to-play requirement, designated party for return-to-play decision, graduated (step by step) return-to-play protocol requirement, responsible party to develop concussion protocols/guidelines requirement, penalties for noncompliance of concussion protocols, and parties that receive liability waivers. The initial collection and review of state concussion statutes was conducted by a primary researcher in June 2015, and three additional researchers independently coded the law and confirmed the initial review for accuracy in December 2015. The coding with divergence was reevaluated by the primary researcher and the sport law experts.

\section{Results}

All 51 states had laws with respect to concussion safety in youth sports. While the vast majority of state statutes were formed based on the framework of the Lystedt Law, there was no standardization among state statutes. Variations were found in several categories, including, but not limited to, youth sport programs applicability, definition of youth sport programs, type of sport activities covered, designated party for removal of athletes, and medical clearance for RTP. The general results of the study can be found in Tables 1-3, while the following sections discuss the results.

\section{Scope and Applicability}

While the primary intent of the concussion statutes is to protect young athletes, an applicable age limit was not specifically stated in many jurisdictions. Only 24 states listed an age in which the laws applied to youth sport participants. Most statutes defined youth to be under the ages of 18 or 19. Few states specified a range of ages, although variations existed (Col. Rev. Stat., 2011, 11-19 years old; Ga. Code, 2013 and La. Rev. Stat., 2011a, 7-19 years old; and Hawaii H.B., 2012, 14-18 years old). In addition, there were states that listed grade levels for a law's applicability (Ia. Code, 2011 and Ms. H.B., 2014, grades 7-12; N.H. Rev. Stat., 2013b, grades 4-12; and N.J. Stat., 2010, grades K-12). Only nine states had statutes that provided a setting for which the legislation would apply with respect to youth sports. For instance, three states (Col. Rev. Stat., 2011; Ga. Code, 2013; and La. Rev. Stat., 2011b) listed public recreation facilities and four states (Ariz. Rev. Stat., 2011; Md. Code, Educ., 2011; N.H. Rev. State., 2013a; and Va. Code, 2014) listed school property as places applicable to the concussion legislation. Slightly more than half $(n=26)$ of the states had a concussion statute that included a definition for youth sport programs. Although there were wide variations among states, common wording in the definitions was "an organized athletic activity in which the participants are engaged in an athletic game or competition against another team, club, or entity, or in practice or preparation for an organized athletic game or competition against another team, club, or entity" (Ark. Code, 2013; Col. Rev. Stat., 2011; Ga. Code, 2013; La. Rev. Stat., 2011a; Mont. Code, 2013; Tenn. Code, 2013a; and Wis. Stat., 2012). Only eight states listed activities that were directly covered by their concussion law. Among these states, football, cheerleading, and physical education classes were common activities in which concussion safety mandates would 


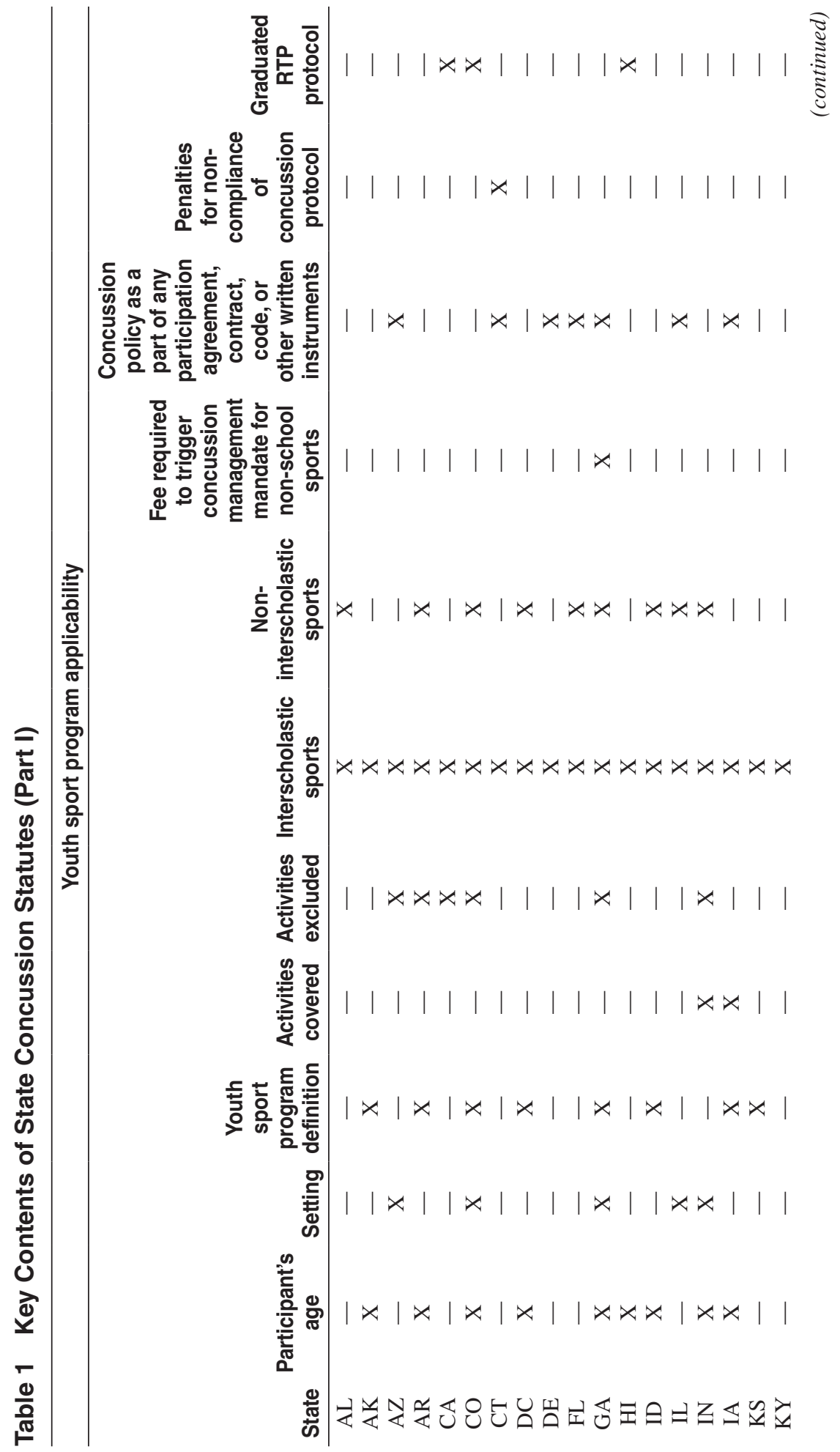




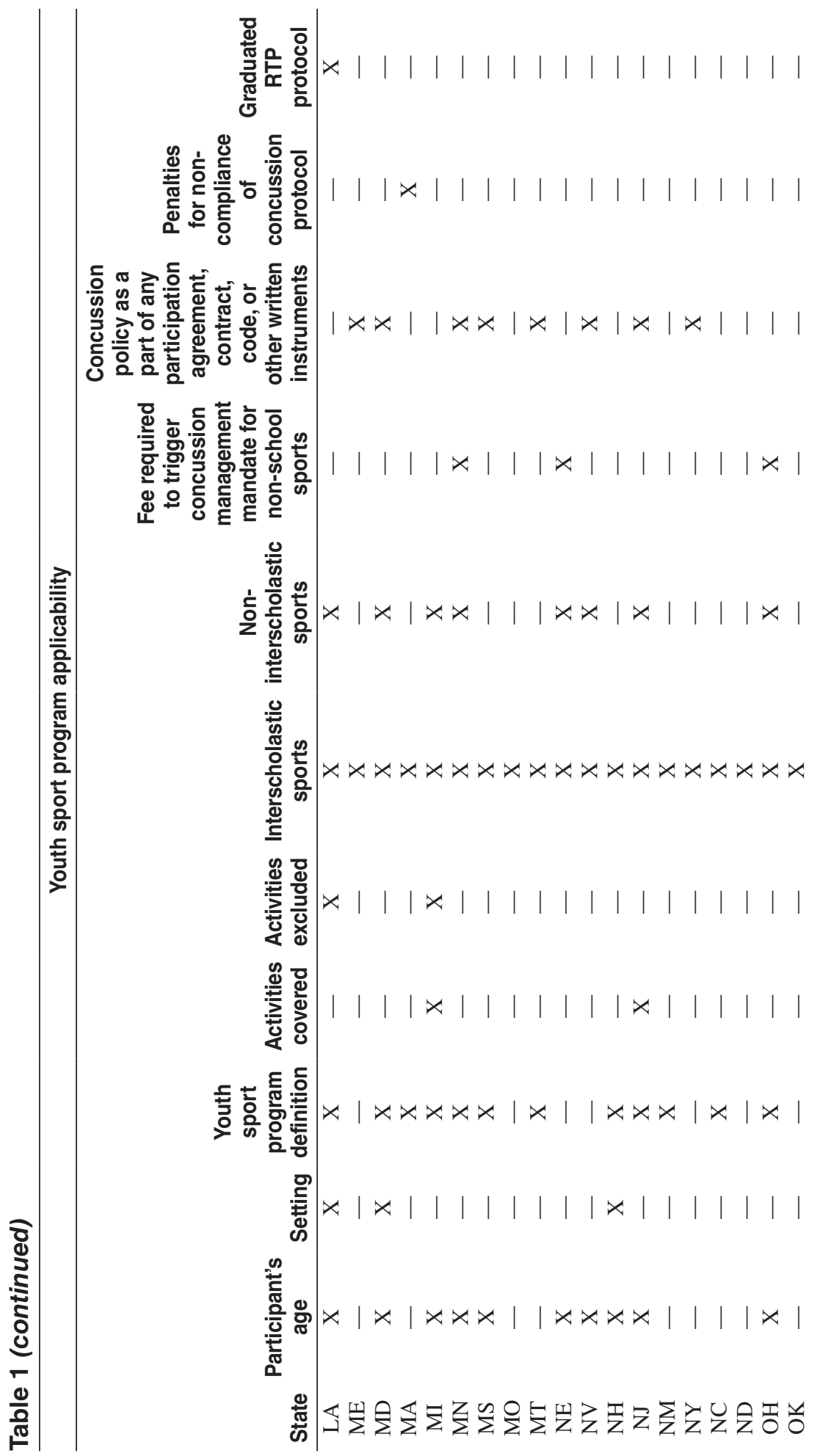




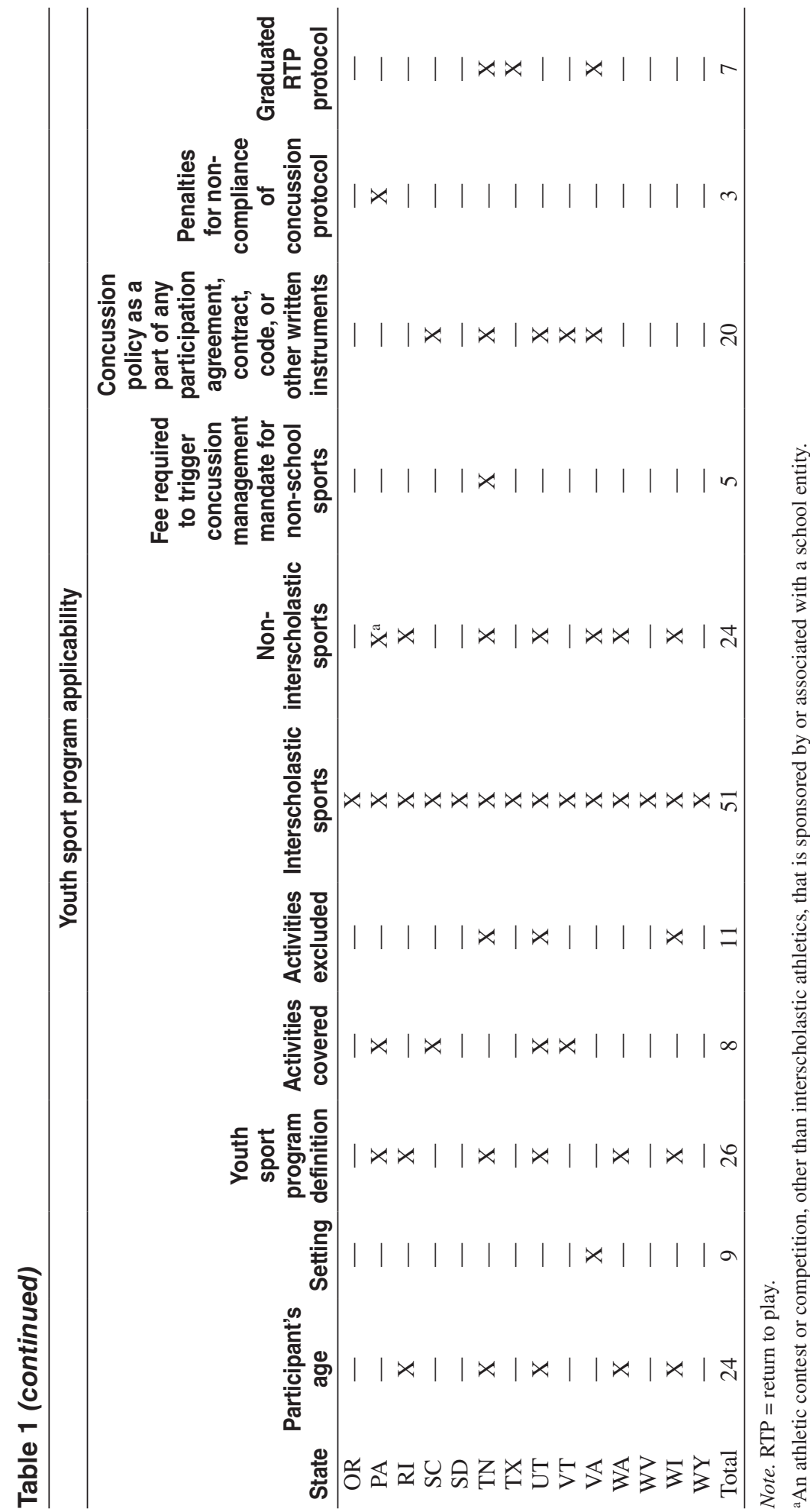


be triggered. On the contrary, 11 states had statutes that contained an excluded list of activities for the law's jurisdiction. "College or university activities" were the most common activities not covered by such statutes. Finally, in regards to youth sport program applicability, all 51 statutes covered interscholastic sports, while less than half $(n=24)$ of the statutes extended the coverage to non-interscholastic programs, which included private clubs, recreational organizations, business, and/or nonprofit organizations. Only five states (Ga. Code, 2013; Minn. Stat., 2011; Neb. Rev. Stat., 2011; Ohio Rev. Code, 2013; and Tenn. Code, 2013b) mentioned a fee requirement that would trigger a concussion safety regulation for non-interscholastic sport programs (Table 1).

\section{Education and Training Requirements}

Most concussion laws also addressed education and training requirements for key youth sport stakeholders (i.e., athletes, coaches, parents/guardians, officials/ referees, etc.). Identified parties are required to be educated or trained in the recognition, management, and evaluation of concussive injuries. The extent of identified parties required to receive concussion safety education varied greatly among statutes, but the most commonly recognized parties were youth athletes, coaches, and the parent/guardian of youth athletes. The vast majority of state legislation required athletes $(n=44)$ and a parent/guardian $(n=48)$ to be educated in some capacity about concussion safety, although education for coaches $(n=29)$ was less common. However, the specific method of education was not stated in many statutes. In fact, parties that are more directly involved in a supervisory role, such as coaches, referees/officials, and athletic trainers were required to undergo more formal concussion safety training that may incorporate online course and/or on-site meeting. Twenty-nine state statutes required coaches to be trained in some form of concussion safety, but the training requirement for the remaining parties, such as referees/officials $(n=7)$ and athletic trainers $(n=6)$, was less common (Table 2).

\section{Removal From Play and RTP Criteria}

Another important component of concussion legislation is the removal-from-play and return-to-play requirements. Current medical consensus recommends that an athlete be removed immediately from play after sustaining a blow to the head and not return to play until medically cleared to avoid the potential of second impact syndrome (Broglio et al., 2014). Nearly all $(n=47)$ states required athletes to be removed from play if they are suspected of having a concussion. However, the designated party with the authority to remove a potentially concussed athlete was found to be inconsistent among states. Nineteen states required coaches to remove athletes suspected of having a concussion, while other states authorized referees/ officials $(n=12)$, athletic trainers $(n=9)$, and health care providers $(n=10)$ to remove such athletes. It should be noted that a health care provider may include, but is not limited to, licensed physicians, licensed physical therapists, and/or other designated individuals with appropriate medical training (Table 2).

States that had a provision for the removal of a concussed athlete also had a medical clearance requirement. Coupled with a requirement for the removal of an athlete in 47 states, medical clearance for RTP was also required in those states. 


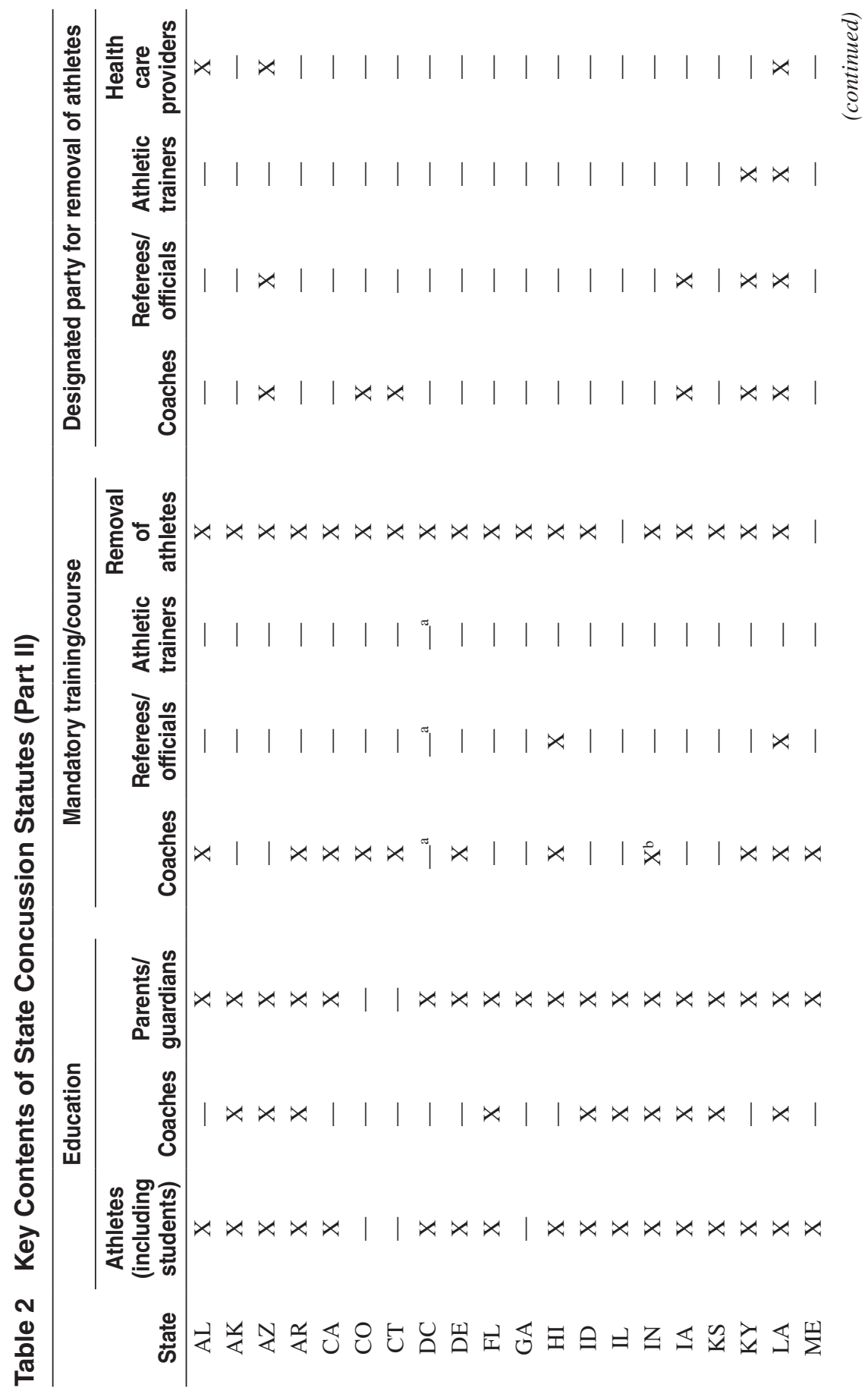




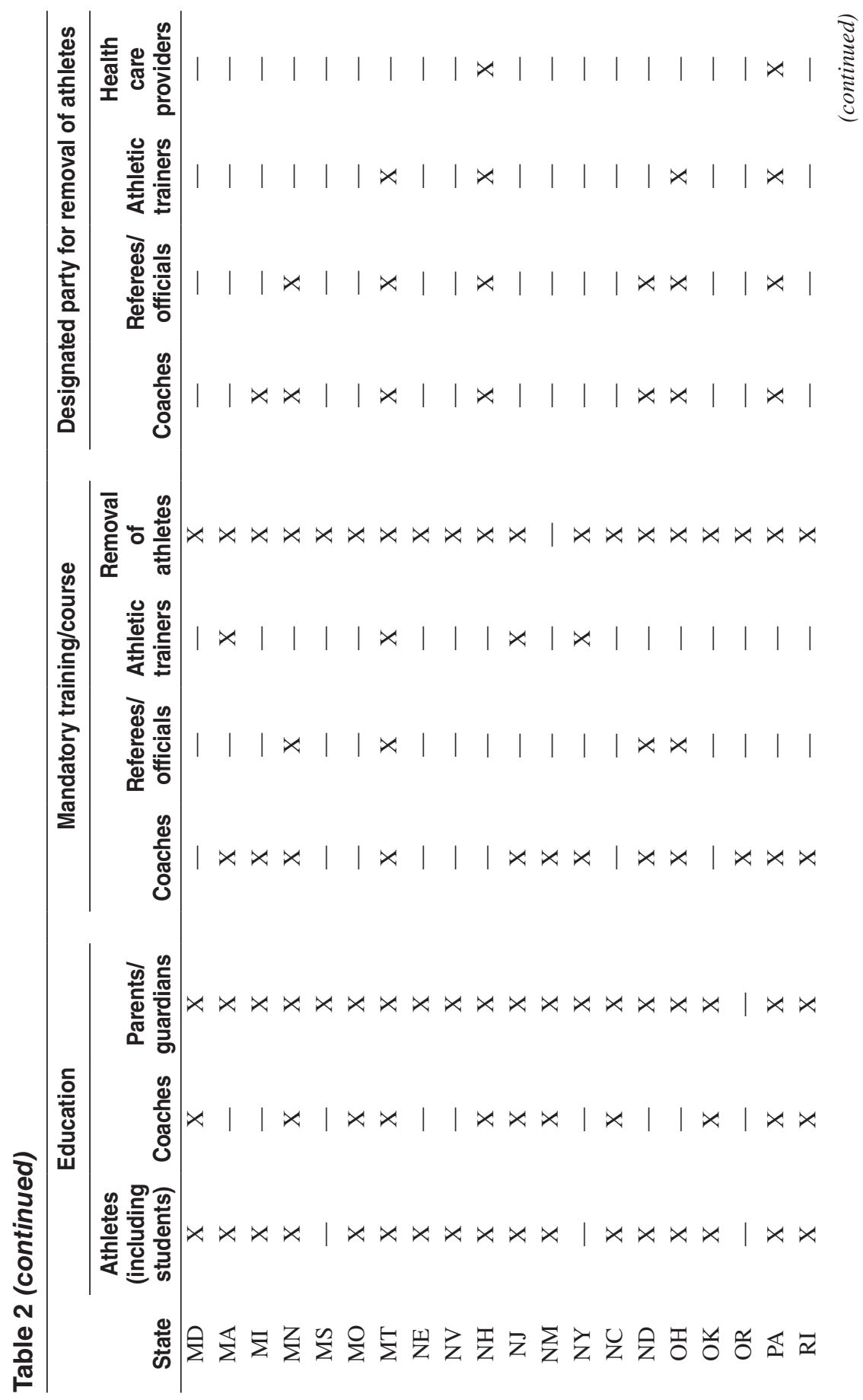

JLAS Vol. 27, No. 2, 2017

173 


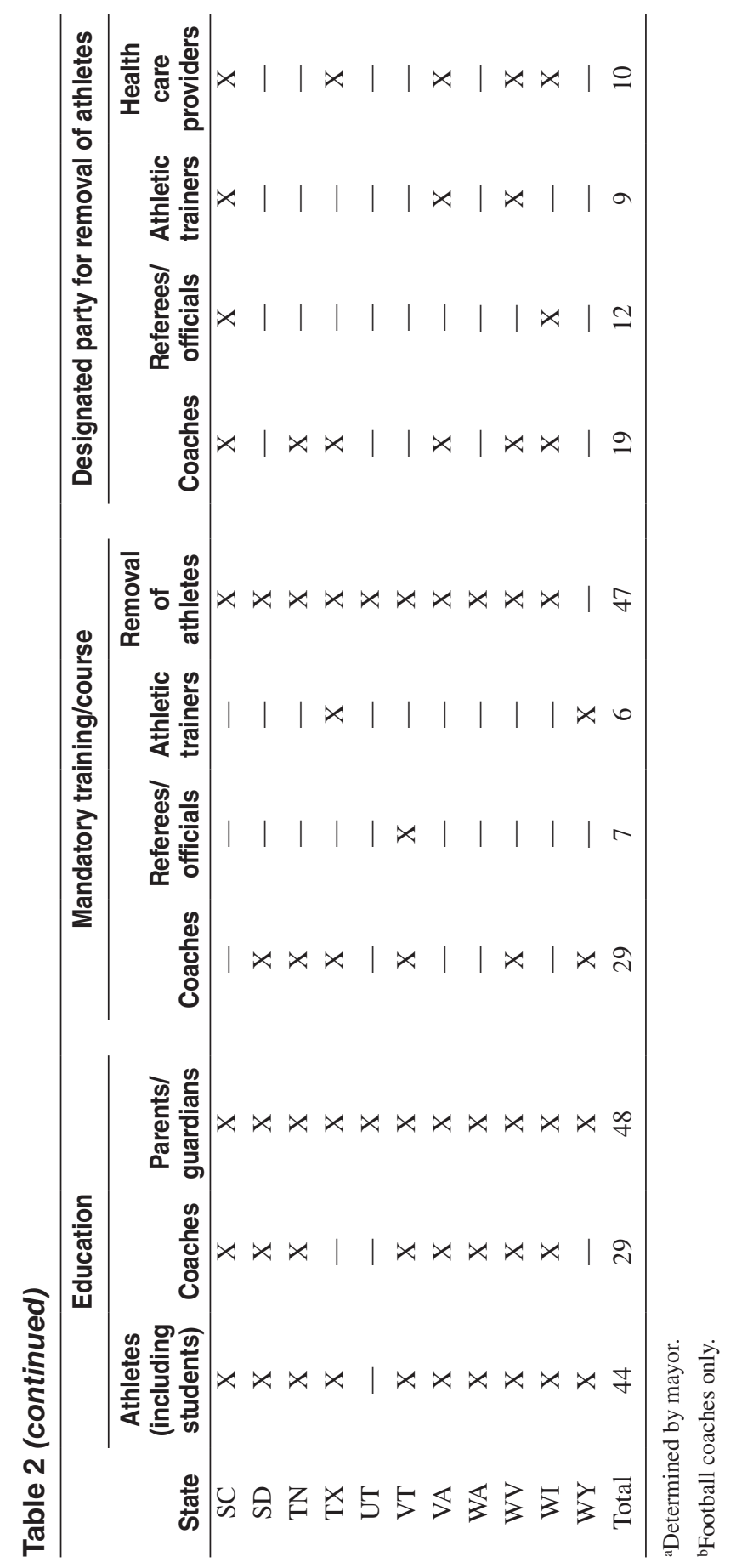


This component requires that a third party evaluate a youth athlete for RTP. A vast majority $(n=46)$ of statutes allowed some form of health care provider to make RTP decisions. Such health care providers may include, but are not limited to, a doctor of chiropractic, medicine, or osteopathic medicine; nurse practitioner; athletic trainer; neuropsychologist; physician assistant; physical therapist; and psychologist. However, a concussion-specific training requirement for these individuals was found in slightly over half $(n=25)$ of the statutes (Table 3$)$.

\section{Liability Waivers for Youth Sport Stakeholders}

Some concussion statutes $(n=17)$ provided legal protection for certain parties from civil liability (i.e., ordinary negligence) arising from concussion-related injuries or death provided they acted in good faith and according to the statutory requirements. Twenty-four states exculpate certain parties that comply with the concussion safety mandates. Specifically, 17 states provided legal protection for youth sport providers (including school district), followed by volunteers $(n=11)$, health care providers $(n=10)$, and coaches $(n=7)$.

\section{Responsible Party to Develop a Safety Protocol/Guideline}

Many states designated certain parties as responsible for developing concussion safety protocols or guidelines as part of the legislative requirements. These designated parties are responsible for developing the concussion safety protocols or guidelines for youth sport programs covered under their state statute. Thirty state statutes designated governing bodies of youth sport programs as those responsible for developing concussion safety protocols/guidelines. Such governing bodies may include school districts and/or recreational youth sport organizations. In addition, 16 states designated the Department of Health and 18 states designated the Department of Education as responsible for developing such protocols/guidelines. Twenty-two state statutes did not identify any parties as responsible for developing concussion safety protocols/guidelines (Table 3).

\section{Other Key Statutory Provisions}

There are a few other noteworthy provisions that were found in many concussion statutes. First, 20 states required a concussion safety policy to be a part of any participation agreements between a youth sport provider and a participant. With the utilization of such participatory agreements, concussion safety policies are more likely to be disseminated to youth athletes and/or their parents and guardians. Furthermore, in some jurisdictions that have such mandates, it is required that youth athletes and/or their parents and guardians sign a form acknowledging receipt of such information. However, concrete details of the educational components to be included in the participatory agreements were not stated in most statutes (Table 1).

Another component that was included in some statutes is the potential penalty that may be imposed on responsible parties that fail to comply with statutory provisions. Although noncompliance procedures are an effective way to enforce statutory requirements, only three states had such provisions (Conn. Gen. Stat., 2013; Mass. Gen. Laws, 2010; and 24 PA Cons. Stat., 2011a). However, they were 


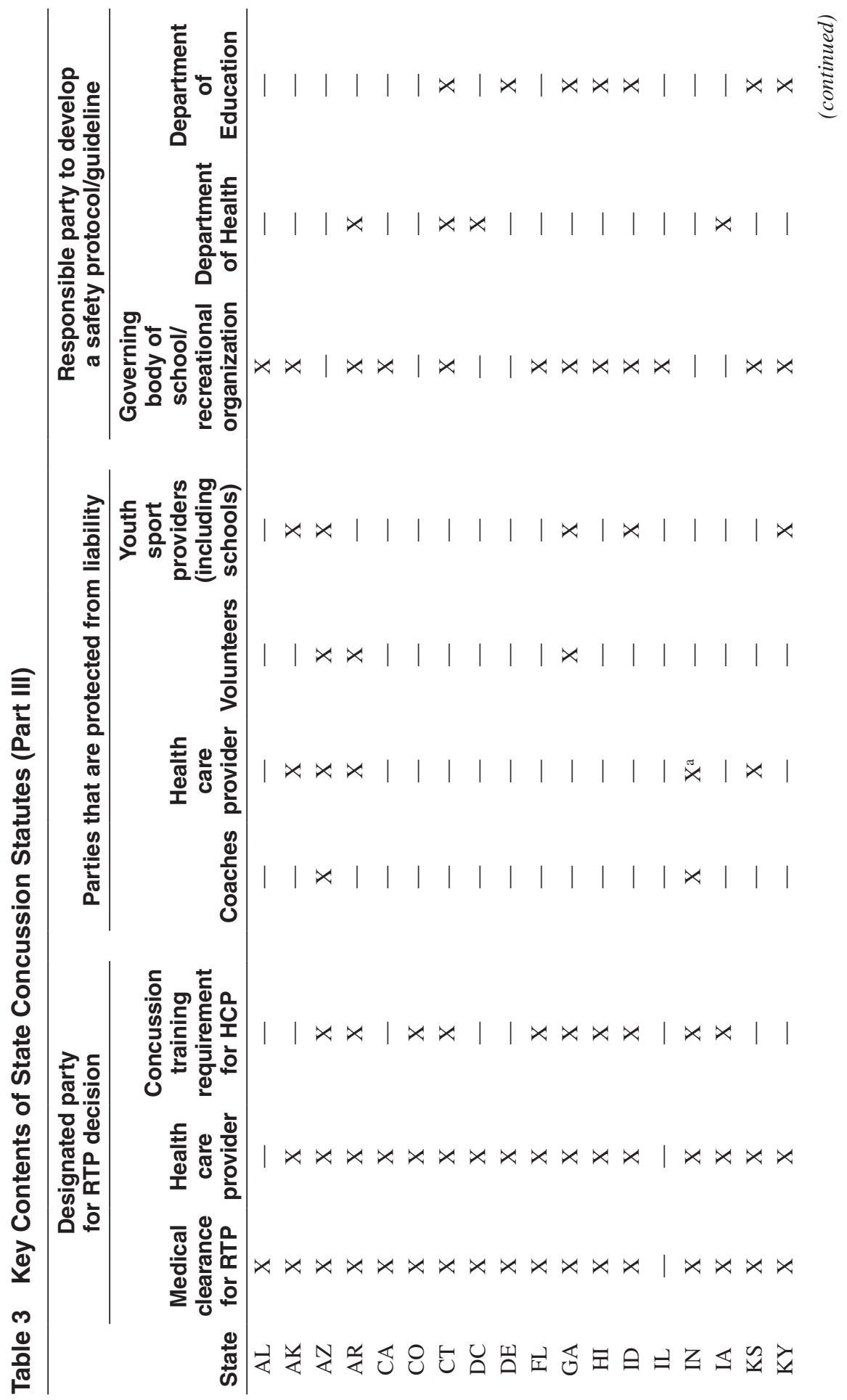




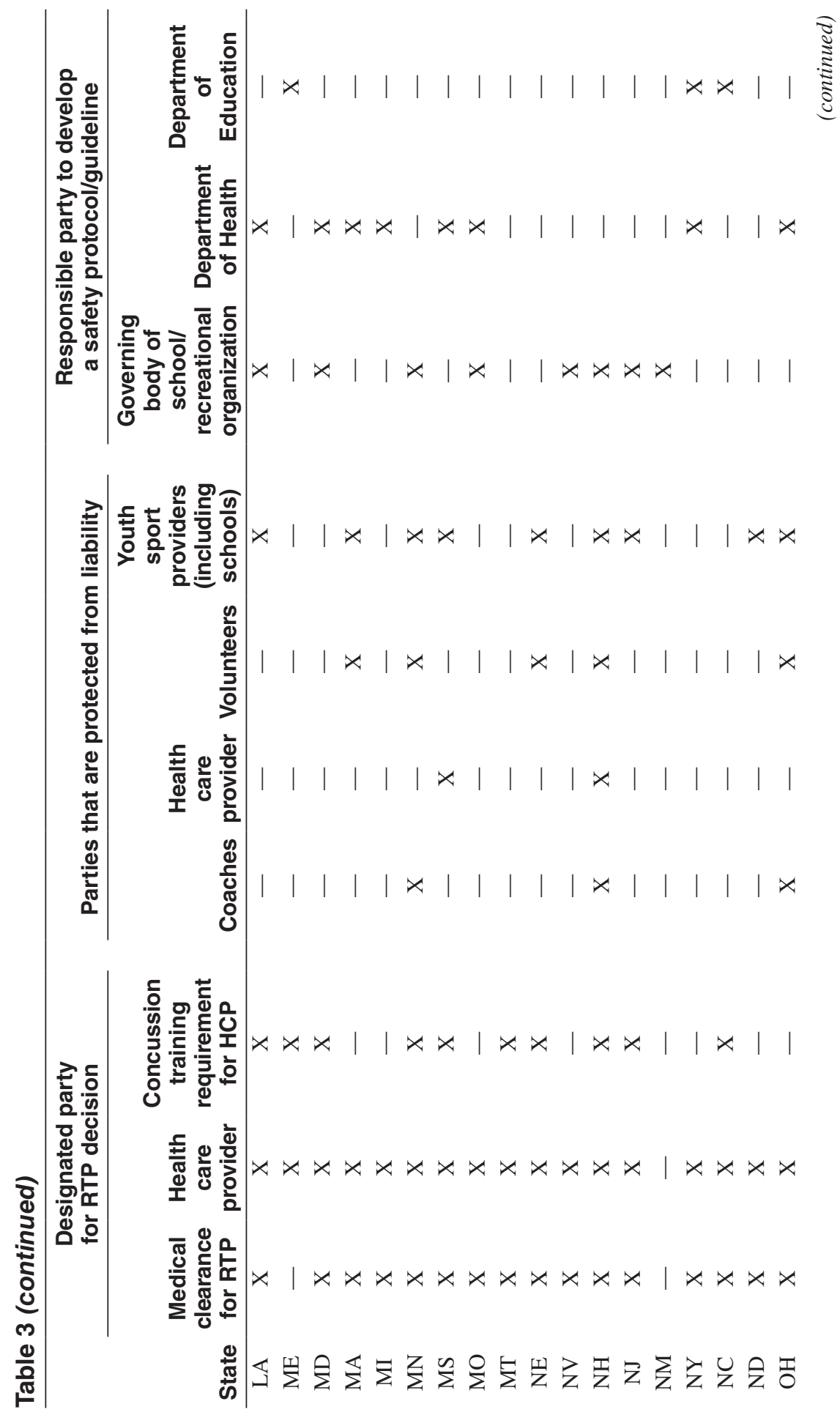




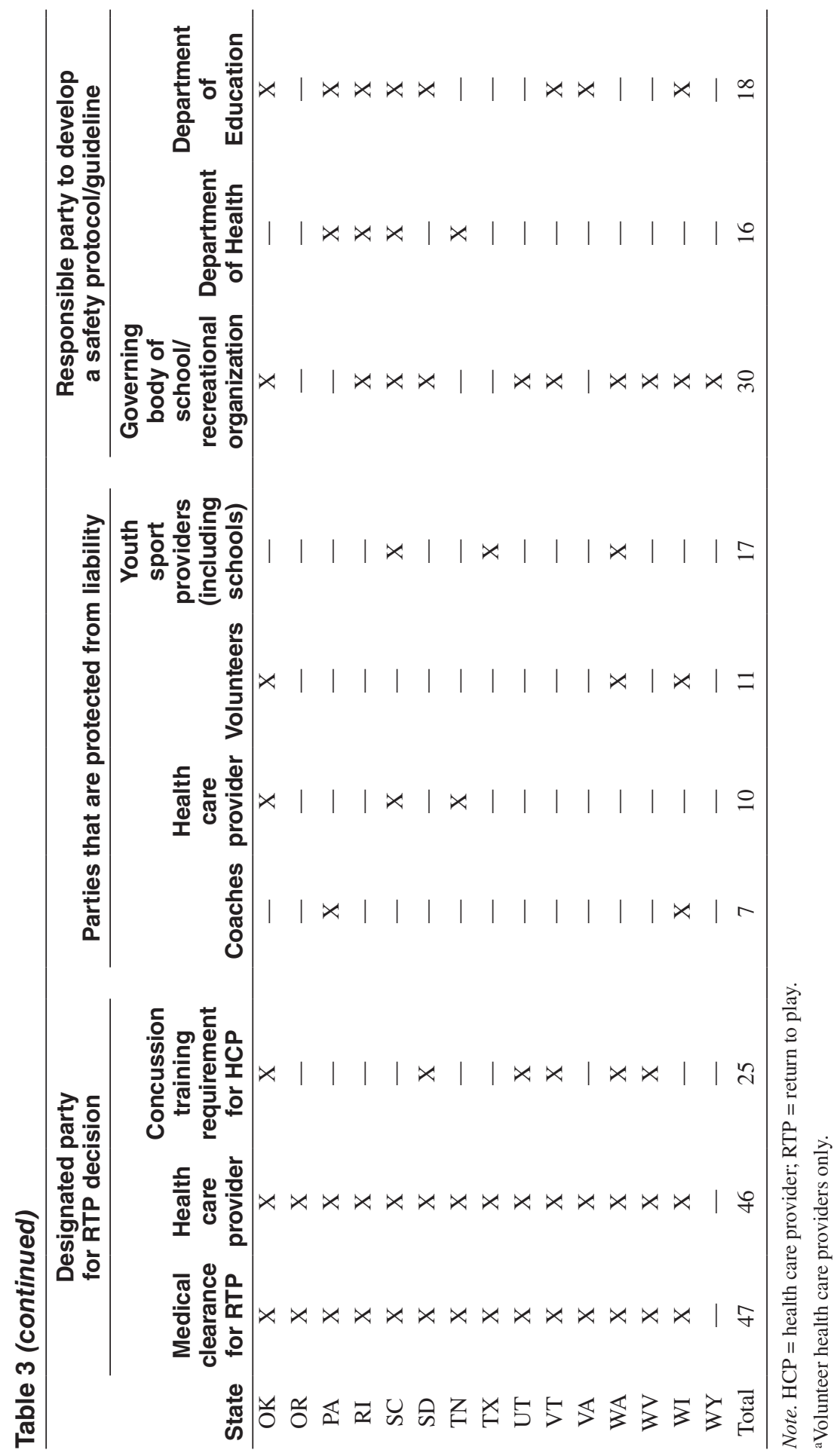


only applicable to interscholastic sports. Coaches who violate the law in Connecticut (Conn. Gen. Stat., 2013) and Pennsylvania (24 PA. Cons. Stat., 2011b) may be subject to suspension from coaching and/or revocation of their coaching permit. The law in Massachusetts (Mass. Gen. Laws, 2010) offered penalties to be determined by the Department of Health in the event of noncompliance (Table 1).

Finally, as shown in Table 1, seven states included language in the law that requires an athlete suspected of incurring a concussion to go through a graduated RTP protocol. This protocol consists of a stepwise progression in which a concussed athlete may gradually increase a level of activity as long as they are asymptomatic at a particular stage. There are six stages in this protocol, with each step taking a minimum of $24 \mathrm{hr}$ (McCrory et al., 2009).

\section{Discussion}

The primary objective of instituting concussion laws has been to increase the general awareness of concussions, remove athletes suspected of being concussed, and stipulate RTP guidelines for those diagnosed with a concussion. Previous research (Bompadre et al., 2014; Chrisman et al., 2014; Rivara et al., 2014; Shenouda, Hendrickson, Davenport, Barber, \& Bell, 2012) has demonstrated early success of concussion legislation in terms of raising overall knowledge and awareness of concussion safety among relevant stakeholders, including coaches, parents/ guardians, and athletes. Nevertheless, state legislators have continued to work with clinicians, epidemiologists, and sport governing bodies to enhance the effectiveness of concussion legislation. Given that concussion laws vary among states, which poses potential challenges in interpretation and implementation, state legislators should consider clarifying language found in these laws.

Only a handful of state concussion statutes define specific sport activities that are covered under these laws. Although 26 states provide a definition of youth sport programs, it is uncertain whether the coverage is inclusive of all sports. Generally speaking, various state statutes have primarily targeted sports with the highest incidents of concussions, such as football, soccer, ice hockey, and lacrosse. However, it is important to include other sports and activities with high concussion rates within these statutes. A recent study found that $36 \%$ of 1,500 water polo athletes suffered at least one concussion during practices or games. Goalies had the highest incidence of concussion, with $47 \%$ of respondents having reported suffering at least one concussion (Blumenfeld, Winsell, Hicks, \& Small, 2016). In addition, concussions have been frequently reported among cheerleaders, but only four state statutes specifically addressed cheerleading. (Ia. Code, 2011; N.J. Stat., 2010; 24 PA. Cons. Stat., 2011a; and S.C. Code, 2013). Although cheerleading may not always be classified as a sport, experts believe that a higher incidence and severity of injuries creates a need that cheerleaders be treated as athletes (Salamon, 2015).

While all of the state concussion laws cover interscholastic athletes, the present review indicate that only 24 states extended coverage to nonschool sports. This implies that other providers of youth sport opportunities, often recreational in nature, might be not obligated to follow the requirements stated in concussion safety statutes despite the fact that approximately $60 \%$ of youth sport participants in the United States are involved in nonschool sport programs (Statistic Brain, 2015). 
In addition, the number of youth who are involved in recreational football leagues is reported to be around three million, which is triple the amount of interscholastic football participants (Landau, 2013). With the high number of youth athletes involved in sports outside of school, statutory language should include these types of recreational organizations.

Education remains one of the primary avenues for improving awareness, recognition, and management of concussions (Halstead \& Walter, 2010). Although the vast majority of concussion laws include a provision for educating coaches, parents, athletes, and other relevant stakeholders (e.g., officials, athletic trainers), there was no standardization of educational sources or content. As a result, this may hinder the effectiveness of educational efforts. State legislators may consider implementing commonly accepted educational materials such as the "Head's Up: Concussion in Youth Sports" as a way to improve or ensure educational efforts. Scholars have suggested that this toolkit has proven to be very effective in increasing coaches' overall knowledge of reducing and managing sport-related concussions (Covassin, Elbin, \& Sarmiento, 2012). Individuals assuming a more direct supervisory role (e.g., coaches, referees/officials, athletic trainers) were mandated by law to receive concussion safety training in addition to being educated. According to the present review, only 29 states required coaches to be trained in concussion safety, while training mandates for referees/officials and athletic trainers were much less common. In the state of Kentucky, concussion safety training may be obtained through an approved course taught by a qualified individual and/or through online teaching methods. Moreover, individuals taking the course are required to take an end-of-course examination and pass with a minimum qualifying score to remain on duty (Ky. Rev. Stat., 2013). In some jurisdictions, coaches are required to take a refresher course to maintain their coaching permit. For instance, Connecticut requires coaches to take a refresher course every five years (Conn. Gen. Stat., 2013). With regular advances being made in concussion safety, coaches and other relevant stakeholders should remain updated on the most current standards. In addition to increasing youth sport stakeholder's concussion safety knowledge, educational components of a law might also help to establish "primary assumption of risk," which has often been used as a defense against lawsuits. By informing relevant stakeholders about the risks that are inherent in concussion-prone sports and requiring receipt of information through written acknowledgment (i.e., express assumption of risk), youth sport organizations might limit liability should concussive injuries to participants result in a lawsuit (Baugh, Kroshus, Bourlas, \& Perry, 2014).

Another major source of inconsistency in language among state statutes was the determination of the appropriate personnel for making RTP decisions. The majority of state laws listed a general health care provider as the responsible party for medically clearing a concussed athlete to return to sports, while only a few jurisdictions specifically identified personnel such as athletic trainer, physician, nurse practitioner, and neuropsychologist responsible for making such decisions. Unfortunately, there has been no medical consensus on standard diagnostic procedures or professional qualifications necessary to successfully clear athletes (Harvey, 2013). Nevertheless, state legislatures should consider authorizing only those with concussion-specific training to decide whether an athlete is symptom-free and reasonably safe to return to an activity. At the time of this review, only 25 states required a health care provider to have concussion-specific training to make RTP decisions 
for concussion-diagnosed athletes, while the remaining states allowed health care providers, without requiring such training, to make RTP decisions. Considering the complexity of diagnosing concussions, future legislative amendments should mandate concussion-specific training as a prerequisite for health care providers.

Despite the fact that legislative interventions are often more efficacious when punitive measures are levied, only three concussion statutes had such noncompliance procedures. As illustrated in studies that analyzed both seat belt and bicycle helmet legislation, imposing punitive measures (e.g., fines) increased compliance (Ji, Gilchick, \& Bender, 2006; Rivara, Thompson, \& Cummings, 1999). Currently, concussion statutes that have penalties for noncompliance are mainly limited to suspension and/or revocation of a coaching permit. However, successful implementation of concussion laws may require that certain sanctions be put in place to discourage responsible parties from neglecting their duties. Meanwhile, those who comply with the legislative provisions should be afforded liability protection for ordinary negligence. The current findings revealed that less than two-thirds of all 51 state statutes did not offer protection from liability. In recent years, lawsuits have been brought against coaches, school nurses, school district/associations, and governing bodies of youth sport programs for negligence and substandard management of concussive injuries (Brady, 2016; Cato, 2015; Koran, 2015; SchoepferBochicchio \& Dodds, 2015; Stempel, 2015). Given that relevant stakeholders of youth sports could become a target for civil lawsuits, state legislatures should provide liability protection to those who act in good faith and according to the mandates or recommendations found in concussion legislation.

\section{Recommendations}

State legislatures should consider clarifying concussion legislation to further support provisions that hold the potential to promote health and safety of youth sport participants. For example, neurocognitive testing was mentioned in only a few state statutes, although such testing has been used commonly to diagnose concussions (Tomei et al., 2012). Such testing assists in evaluating concussions and decisions related to RTP. Specifically, the Maddock Questions of Orientation, the NFL Sideline Concussion Assessment Tool, and the Sport Concussion Assessment Tool (SCAT2) are neurocognitive tests that are being used to triage concussed athletes on the sidelines (Putukian, 2011). Neurocognitive testing can also be used before the start of the season to establish baseline values for memory and reaction times. These values can then be used to assess a potential decline in cognitive functioning once an athlete sustains a concussion. However, given that many youth sport programs lack access to the appropriate medical personnel for these neurocognitive evaluations, mini-grants or other funding mechanisms should be mandated in legislation to encourage and support these tests.

The rules of play contributing to sport safety and potential rule changes based on the demographic factors of participants (e.g., age, gender, disabilities) hold the potential to reduce the risk of concussions. Kontos et al. (2016) found that $40 \%$ of incurred concussions in youth ice hockey were due to illegal contact. More importantly, studies have suggested that limiting contact in various sports may reduce the number of concussive injuries. For instance, banning spear tackling in American 
football, preventing body checking from behind in ice hockey, and limiting elbowto-head contact in soccer have been shown to reduce the risk of concussions (Anderson, 2004; Grindel, Lovell, \& Collins, 2001). Recently, U.S. Soccer banned players younger than 11 years old from heading the ball. This decision stemmed from a class-action lawsuit that sought rule changes to reduce concussions (Mehr v. U.S. Soccer, 2014). The Somerville, Massachusetts, Recreation Department also addressed contact issues in football by banning tackling among youth participants in grades 1-8 (Goldman, 2016). Because research suggests that rule changes can reduce the number of concussions, language in legislation that mandates rules of play designed to prevent or reduce the probability of concussions is recommended.

Finally, studies suggest a significantly higher incidence of concussions among 18-year-olds (Echlin et al., 2010) than among 13-14-year-olds (Goodman, Gaetz, \& Meichenbaum, 2001), and female athletes are more likely to sustain concussions with recovery time taking longer than male athletes (Covassin, Elbin, Harris, Parker, \& Kontos, 2012). In addition, based on the sport, football accounted for the highest rate of concussions, followed by female soccer (Gessel, Fields, Collins, Dick, \& Comstock, 2007; Lincoln et al., 2011). Given that risk of concussion may be partly based on demographic factors (e.g., age, gender, type of sports), legislators may consider such data in future amendments (e.g., minimum age requirements for participation, mandatory safety equipment).

\section{Conclusion}

All 51 states have passed concussion statutes with similar provisions: concussion education for youth sport stakeholders, removal of athletes suspected of being concussed, and medical clearance requirements for RTP decisions by appropriate health care providers. However, with state concussion statutes still in the early phases of implementation, the lack of uniform language can inhibit the creation of common or standard practices for reducing and managing concussions. Moreover, state laws are rapidly changing to accommodate the most up-to-date medical consensus, gaps in practices, and research findings. A recent bill in Kentucky amended their RTP provision by authorizing referees to override decisions made by coaches if there is a reasonable suspicion that medical consent has not been obtained (Associated Press, 2016). Florida was the first state to mandate that all high school athletes be educated in concussion safety by watching a video and then signing a form stating they have done so (Sussingham, 2015). Future legislative amendments may also consider extending a law's coverage to nonschool sports, specifying contents of educational requirements, delineating qualified personnel for making RTP decisions, and levying more stringent penalties for noncomplying parties. Finally, legislative components such as requiring neurocognitive testing, primary prevention intervention, and specific and narrowly tailored language to meet demographic characteristics of participants should be considered. Future research that investigates the effectiveness of concussion legislation is also necessary to better understand and support the need for enhanced legislative efforts. Survey research and case studies that examine youth sport stakeholder's knowledge of concussion legislation, perceptions on challenges to compliance, and recommendations on clarifying legislation are suggested. 


\section{References}

Anderson, S.D. (2004). Body-checking in hockey. Canadian Medical Association Journal, $170(1), 16-18$.

Ariz. Rev. Stat. § 15-341 (2011).

Ark. Code § 6-18-710 (2013).

Associated Press. (2016, March 1). Fearing concussions, Kentucky weighs giving referees more power. WHAS11. Retrieved January 14, 2016 from http://www.whas11.com/ news/politics/fearing-concussions-ky-weighs-giving-referees-more-power/63241164

Bakhos, L.L., Lockhart, G.R., Myers, R., \& Linakis, J.G. (2010). Emergency department visits for concussion in young child athletes. Pediatrics, 126(3), 958-963. doi:10.1542/ peds.2009-3101

Baugh, C.M., Kroshus, E., Bourlas, A.B., \& Perry, K.I. (2014). Requiring athletes to acknowledge receipt of concussion-related information and responsibility to report symptoms: A study of the prevalence, variation, and possible efficacy. The Journal of Law, Medicine \& Ethics, 42(3), 297-313. doi:10.1111/jlme.12147

Benson, B.W., McIntosh, A.S., Maddocks, D., Herring, S.A., Raftery, M., \& Dvořák, J. (2013). What are the most effective risk-reduction strategies in sport concussion? British Journal of Sports Medicine, 47(5), 321-326. doi:10.1136/bjsports-2013-092216

Bey, T., \& Ostick, B. (2009). Second impact syndrome. The Western Journal of Emergency Medicine, 10(1), 6-10.

Blumenfeld, R.S., Winsell, J.C., Hicks, J.W., \& Small, S.L. (2016). The epidemiology of sports-related head injury and concussion in water polo. Frontiers in Neurology, 7(98), 1-11.

Bompadre, V., Jinguji, T.M., Yanez, N.D., Satchell, E.K., Gilbert, K., Burton, M., . . . Herring, S.A. (2014). Washington State's Lystedt Law in concussion documentation in Seattle public high schools. Journal of Athletic Training, 49(4), 486-492. doi:10.4085/10626050-49.3.30

Brady, E. (2016, March). Could Pop Warner settlement signal the end of football? Athletic Business. Retrieved March 30 from http://www.athleticbusiness.com/law-policy/couldsettlement-of-pop-warner-case-signal-the-end-of-football.html

Broglio, S.P., Cantu, R.C., Gioia, G.A., Guskiewicz, K.M., Kutcher, J., Palm, M., \& Mcleod, T.C. (2014). National Athletic Trainers' Association position statement: Management of sport concussion. Journal of Athletic Training, 49(2), 245-265. doi:10.4085/10626050-49.1.07

Cal. Educ. Code $\$ 17581$ (2014a).

Cal. Educ. Code $\$ 49475$ (2014b).

Cantu, R.C., \& Register-Mihalik, J.K. (2011). Considerations for return-to-play and retirement decisions after concussion. $P M \& R, 3(10$, Suppl. 2) S440-S444. doi:10.1016/j. pmrj.2011.07.013

Castile, L., Collins, C.L., McIlvain, N.M., \& Comstock, R.D. (2012). The epidemiology of new versus recurrent sports concussions among high school athletes, 2005-2010. British Journal of Sports Medicine, 46, 603-610. doi:10.1136/bjsports-2011-090115

Cato, J. (2015, December). Lawsuit alleges PIAA failed to protect students from concussions. Trib Live. Retrieved March 23, 2016, from http://triblive.com/news/adminpage/9611933-74/lawsuit-athletes-concussion

Chrisman, S.P., Schiff, M.A., Chung, S.K., Herring, S.A., \& Rivara, F.P. (2014). Implementation of concussion legislation and extent of concussion education for athletes, parents, and coaches in Washington State. American Journal of Sports Medicine, 42(5), 1190-1196. doi:10.1177/0363546513519073

Col. Rev. Stat. § 25-43-102 (2011).

Covassin, T., Elbin, R.J., Harris, W., Parker, T., \& Kontos, A. (2012). The role of age and sex in symptoms, neurocognitive performance, and postural stability in ath- 
letes after concussion. American Journal of Sports Medicine, 40(6), 1303-1312. doi:10.1177/0363546512444554

Covassin, T., Elbin, R.J., \& Sarmiento, K. (2012). Educating coaches about concussion in sports: Evaluation of the CDC's "Heads Up: Concussion in Youth Sports" initiative. The Journal of School Health, 82(5), 233-238. doi:10.1111/j.1746-1561.2012.00692.x Conn. Gen. Stat. § 10-149b (2013).

Echlin, P.S., Tator, C.H., Cusimano, M.D., Cantu, R.C., Taunton, J.E., Upshur, R.E., . . \& \& Skopelja, E.N. (2010). A prospective study of physician-observed concussions during junior ice hockey: Implications for incidence rates. Neurosurgical Focus, 29(5), E4. doi:10.3171/2010.9.FOCUS10186

Ga. Code $\$ 20-2-324.1$ (2013).

Gessel, L.M., Fields, S.K., Collins, C.L., Dick, R.W., \& Comstock, R.D. (2007). Concussions among United States high school and collegiate athletes. Journal of Athletic Training, 42, 495-503.

Gianotti, S., \& Hume, P.A. (2007). Concussion sideline management intervention for rugby union leads to reduced concussion claims. NeuroRehabilitation, 22(3), 181-189.

Gibson, T.B., Herring, S.A., Kutcher, J.S., \& Broglio, S.P. (2015). Analyzing the effect of state legislation on health care utilization for children with concussion. JAMA Pediatrics, 169(2), 163-168. doi:10.1001/jamapediatrics.2014.2320

Giguere, A., Legare, F., Grimshaw, J., Turcotte, S., Fiander, M., Grudniewicz, A., . . Gagnon, M. (2012). Printed educational materials: Effects on professional practice and healthcare outcomes. Cochrane Database of Systematic Reviews, Issue 10. Art. No.: CD004398. doi:10.1002/14651858.CD004398.pub3

Goldman, S. (2016, January). Boston suburb bans tackling in youth football program. Athletic Business. Retrieved from http://www.athleticbusiness.com/recreation/boston-suburbbars-tackling-in-youth-football.html

Goodman, D., Gaetz, M., \& Meichenbaum, D. (2001). Concussions in hockey: There is cause for concern. Medicine and Science in Sports and Exercise, 33(12), 2004-2009. doi:10.1097/00005768-200112000-00005

Gourley, M.M., Valovich McLeod, T.C., \& Bay, R.C. (2010). Awareness and recognition of concussion by youth athletes and their parents. Athletic Training \& Sports Health Care, 2(5), 208-218.

Grindel, S.H., Lovell, M.R., \& Collins, M.W. (2001). The assessment of sport-related concussion: The evidence behind neuropsychological testing and management. Clinical Journal of Sport Medicine, 11(3), 134-143. doi:10.1097/00042752-200107000-00003

Halstead, M.E., \& Walter, K.D. (2010). Sport-related concussion in children and adolescents. Pediatrics, 126(3), 597-615. doi:10.1542/peds.2010-2005

Harmon, K.G., Drezner, J.A., Gammons, M., Guskiewicz, K.M., Halstead, M., Herring, S.A., . . Roberts, W.O. (2013). American Medical Society for Sports Medicine position statement: Concussion in sport. British Journal of Sports Medicine, 47(1), 15-26. doi:10.1136/bjsports-2012-091941

Harvey, H.H. (2013). Reducing traumatic brain injuries in youth sports: Youth sports traumatic brain injury state laws, January 2009-December 2012. American Journal of Public Health, 103(7), 1249-1254. doi:10.2105/AJPH.2012.301107

Hawaii H.B. 2273 S.D. 1 (2012).

Ia. Code $\S 280.13 \mathrm{C}(2011)$.

Ji, M., Gilchick, R.A., \& Bender, S.J. (2006). Trends in helmet use and head injuries in San Diego County: The effect of bicycle helmet legislation. Accident, Analysis and Prevention, 38, 128-134. doi:10.1016/j.aap.2005.08.002

Karlin, A.M. (2011). Concussion in the pediatric and adolescent population: Different population, different concerns. $P M \& R, 3$ (10, Suppl. 2) S369-S379. doi:10.1016/j. pmrj.2011.07.015 
Kim, S., Spengler, J.O., \& Connaughton, D.P. (2016). An exploratory study of concussion management policies in municipal park and recreation departments. Journal of Policy Research in Tourism, Leisure and Events, 8(3), 274-288. doi:10.1080/19407963.201 6.1181077

Kontos, A.P., Elbin, R.J., Sufrinko, A., Dakan, S., Bookwalter, K., Price, A., . . . Collins, M.W. (2016). Incidence of concussion in youth ice hockey players. Pediatrics, 137(2), 1-6. doi:10.1542/peds.2015-1633

Ky. Rev. Stat. $§ 160.445$ (2013).

Landau, E. (2013, September 2). High schools tackle football concussions. CNN. Retrieved December 15, 2015, from http://www.cnn.com/2013/08/30/health/high-school-footballsafety/index.html

Langlois, J.A., Rutland-Brown, W., \& Wald, M.M. (2006). The epidemiology and impact of traumatic brain injury. The Journal of Head Trauma Rehabilitation, 21(5), 375-378. doi:10.1097/00001199-200609000-00001

La. Rev. Stat. § 40:1299.182 (2011a).

La. Rev. Stat. § 40:1299.183 (2011b).

Lincoln, A.E., Caswell, S.V., Almquist, J.L., Dunn, R.E., Norris, J.B., \& Hinton, R.Y. (2011). Trends in concussion incidence in high school sports: A prospective 11-year study. American Journal of Sports Medicine, 39, 958-963. doi:10.1177/0363546510392326

Lowrey, K. (2014). State laws addressing youth sports-related traumatic brain injury and the future of concussion law and policy. Journal of Business \& Technology Law, 10(1), 61-72.

Lowrey, K., \& Morain, S. (2014). State experiences implementing youth sports concussion laws: Challenges, success, and lessons for evaluating impact. The Journal of Law, Medicine \& Ethics, 42(3), 290-296. doi:10.1111/jlme.12146

Koran, M. (2015, January). Former high school football player sues school district after coaches reinsert him in game. Voice of San Diego. Retrieved January 14, 2016, from http://www.voiceofsandiego.org/all-narratives/concussions-2/la-jolla-high-footballcoaches-point-fingers-after-students-brain-injury/

Mackenzie, B., Vivier, P., Reinert, S., Machan, J., Kelley, C., \& Jacobs, E. (2015). Impact of a state concussion law on pediatric emergency department visits. Pediatric Emergency Care, 31(1), 25-30. doi:10.1097/PEC.0000000000000325

Macpherson, A., Fridman, L., Scolnik, M., Corallo, A., \& Guttmann, A. (2014). A populationbased study of pediatric emergency department and office visits for concussions from 2003 to 2010. Paediatrics \& Child Health, 19(10), 543-546. doi:10.1093/pch/19.10.543

Marar, M., McIlvain, N.M., Fields, S.K., \& Comstock, R.D. (2012). Epidemiology of concussions among United States high school athletes in 20 sports. American Journal of Sports Medicine, 40, 747-755. doi:10.1177/0363546511435626

Mass. Gen. Laws ch. 111, § 222 (2010).

McCrory, P., Meeuwisse, W., Johnston, K., Dvorak, J., Aubry, M., Molloy, M., \& Cantu, R. (2009). Consensus statement on concussion in sport: The 3rd International Conference on Concussion in Sport held in Zurich, November 2008. British Journal of Sports Medicine, 43(Suppl. 1), i76-i90. doi:10.1136/bjsm.2009.058248

Md. Code, Educ. § 7-433 (2011).

Meehan, W.P., d'Hemecourt, P., \& Comstock, R.D. (2010). High school concussions in the 2008-2009 academic year: Mechanism, symptoms, and management. American Journal of Sports Medicine, 38, 2405-2409. doi:10.1177/0363546510376737

Mehr v. U.S. Soccer, No. 14-cv-3879 (2014).

Minn. Stat. § 121A.37 (2011).

Mont. Code $§ 20-7-1302$ (2013).

Ms. H.B. 48, Reg. Sess. (2014).

Neb. Rev. Stat. § 71-9105 (2011).

N.H. Rev. (2013a). Stat, 200, 51. 
N.H. Rev. (2013b). Stat, 200, 52.

N.J. Stat. § 18A:40-41.3 (2010).

Ohio Rev. Code $\$ 3707.51$ (2013).

24. Cons, P.A. (2011a). Stat, § 5322.

24. Cons, P.A. (2011b). Stat, §5323.

Public Health Law Research. (2015). Youth sports traumatic brain injury laws map. Retrieved July 15, 2015, from http://lawatlas.org/query?dataset=sc-reboot

Putukian, M. (2011). The acute symptoms of sport-related concussion: Diagnosis and on-field management. Clinical Journal of Sport Medicine, 30, 49-61. doi:10.1016/j. csm.2010.09.005

Rivara, F.P., Schiff, M.A., Chrisman, S.P., Chung, S.K., Ellenbogen, R.G., \& Herring, S.A. (2014). The effect of coach education on reporting of concussions among high school athletes after passage of a concussion law. American Journal of Sports Medicine, 42(5), 1197-1203. doi:10.1177/0363546514521774

Rivara, F.P., Thompson, D.C., \& Cummings, P. (1999). Effectiveness of primary and secondary enforced seat belt laws. American Journal of Preventive Medicine, 16(1, Suppl.) 30-39. doi:10.1016/S0749-3797(98)00113-5

Rosenthal, J.A., Foraker, R.E., Collins, C.L., \& Comstock, R.D. (2014). National high school athlete concussion rates from 2005-2006 to 2011-2012. American Journal of Sports Medicine, 42(7), 1710-1715. doi:10.1177/0363546514530091

Salamon, M. (2015, December). Concussions are biggest health risk to cheerleaders. HealthDay. Retrieved July 26, 2016, from https://consumer.healthday.com/cognitive-healthinformation-26/concussions-news-733/as-cheerleading-becomes-more-competitiveconcussions-top-list-of-injuries-study-says-706029.html

S.C. Code $\$ 59-63-75$ (2013).

Schoepfer-Bochicchio, K., \& Dodds, M. (2015, October). Concussion lawsuit examines school nurse's duty of care. Athletic Business. Retrieved November 22, 2015, from http://www.athleticbusiness.com/civil-actions/concussion-lawsuit-examines-schoolnurse-s-duty-of-care.html

Shenouda, C., Hendrickson, P., Davenport, K., Barber, J., \& Bell, K.R. (2012). The effects of concussion legislation one year later-What have we learned: A descriptive pilot survey of youth soccer player associates. $P M \& R, 4(6), 427-435$. doi:10.1016/j. pmrj.2012.02.016

Statistic Brain. Youth Sport Statistics. Retrieved July 26, 2015, from http://www.statisticbrain. com/youth-sports-statistics/

Stempel, J. (2015, July). FIFA, others, defeat U.S. soccer concussion lawsuit. Reuters. Retrieved December 15, 2015, from http://www.reuters.com/article/us-soccer-concussions-fifa-lawsuit-idUSKCNOPR1JN20150717

Sussingham, R. (2015, August). Florida first state to require concussion training for high school athletes. State-Impact. Retrieved January 12, 2016, from https://stateimpact. npr.org/florida/2015/08/31/florida-first-state-to-require-concussion-training-for-highschool-athletes/

Tenn. Code $§ 68-55-501$ (2013a).

Tenn. Code $\$ 68-55-503(2013 b)$.

Tex. Educ. Code § 33.094 (2011).

Thomas, M., Haas, T.S., Doerer, J.J., Hodger, J.S., Aicher, B.O., Garberich, R.F., . . Maron, B.J. (2011). Epidemiology of sudden death in young, competitive athletes due to blunt trauma. Pediatrics, 128(1), E1-E8. doi:10.1542/peds.2010-2743

Tomei, K.L, Doe, C., Prestigiacomo, C.J., \& Gandhi, C.D. (2012). Comparative analysis of state-level concussion legislation and review of current practices in concussion. Neurosurgical Focus, 33(6), E11, 1-9.

Va. Code $§ 22.1-271.5$ (2014).

Wis. Stat. § 118.293 (2012). 